\title{
Relative tectonics and debris flow hazards in the Beijing mountain area from DEM-derived geomorphic indices and drainage analysis
}

\author{
Weiming Cheng a,d,*, Nan Wang a,b, Min Zhao ${ }^{\mathrm{a}, \mathrm{b}}$, Shangmin Zhao ${ }^{\mathrm{c}}$ \\ a State Key Laboratory of Resources and Environmental Information Systems, Institute of Geographic and Natural Resources Research, Chinese Academy of Sciences, Beijing 100101, China \\ ${ }^{\mathrm{b}}$ University of Chinese Academy of Sciences, Beijing 100049, China \\ c Department of Surveying and Mapping, College of Mining Engineering, Taiyuan University of Technology, Taiyuan 030024,China \\ d Jiangsu Center for Collaborative Innovation in Geographical Information Resource Development and Application, Nanjing 210023, China
}

\section{A R T I C L E I N F O}

\section{Article history:}

Received 12 December 2014

Received in revised form 6 January 2016

Accepted 8 January 2016

Available online 12 January 2016

\section{Keywords:}

Beijing mountain area

Debris flows

Geomorphic indices

IRAT

\begin{abstract}
A B S T R A C T
The geomorphic setting of the tectonically active area around Beijing is a result of complex interactions involving Yanshan neotectonic movements and processes of erosion and deposition. The Beijing Mountain study area contains the junction of two mountain ranges (the Yanshan Mountains and the Taihang Mountains). Tectonic activity has significantly influenced the drainage system and the geomorphic situation in the area, leading to a high probability of the development of debris flows, which is one of the major abrupt geological disasters in the region. Based on 30-m-resolution ASTER GDEM data, a total of 752 drainage basins were extracted using ArcGIS software. A total of 705 debris flow valleys were visually interpreted from ALOS satellite images and published documents. Seven geomorphic indices were calculated for each basin including the relief amplitude, the hypsometric integral, the stream length gradient, the basin shape indices, the fractal dimension, the asymmetry factor, and the ratio of the valley floor width to the height. These geomorphic indices were divided into five classes and the ratio of the number of the debris flow valleys to the number of the drainage basins for each geomorphic index was computed and analyzed for every class. Average class values of the seven indices were used to derive an index of relative active tectonics (IRAT). The ratio of the number of the debris flow valleys to the number of the drainage basins was computed for every class of IRAT. The degree of probable risk level was then defined from the IRAT classes. Finally, the debris flow hazard was evaluated for each drainage basin based on the combined effect of probable risk level and occurrence frequency of the debris flows. The result showed a good correspondence between IRAT classes and the ratio of the number of the debris flow valleys to the number of the drainage basins. Approximately $65 \%$ of the drainage basins with occurred debris flow valleys are at a high risk level, while $43 \%$ of the drainage basins without occurred debris flow valleys are at a high risk level. A comparison with results from past studies demonstrated that the accuracy of these findings is greater than $85 \%$, indicating that the basin topography created by rapid tectonic deformations is more favorable for debris flows.
\end{abstract}

(C) 2016 Elsevier B.V. All rights reserved.

\section{Introduction}

Debris flows are sudden natural disasters that often occur in mountainous regions. These flows consist of fully saturated mixtures of water, sediment and debris that can travel several kilometers, often in a series of surges, in mountainous torrents or across open hillslopes (Iverson, 1997). The higher the elevation of the mountain, the greater the static pressure of the landform, which enhances landfalls, earth slides, mountainous floods and debris flows (Anbalagan and Singh, 1996).

Currently, hazard analysis of debris flows and landslides is typically conducted by establishing a relationship between their cause and

\footnotetext{
* Corresponding author at: State Key Laboratory of Resources and Environmenta Information Systems, Institute of Geographic and Natural Resources Research, Chinese Academy of Sciences, Beijing 100101, China.

E-mail address: chengwm@lreis.ac.cn (W. Cheng).
}

occurrence and assessing their hazard based on the relationship (Carrara, 1991; Mejia-Navarro et al., 1994; Chen and Wang, 2007). The factors used for hazard analysis of debris flows and landslides fall into a number of categories, such as geomorphic, geological, land use/ land cover, and hydrological factors (Lee, 2005). Various approaches for hazard analysis of debris flows and landslides have been developed by many researchers. These approaches include inventory analysis (Hewitt, 1998; Guzzetti, 2000), logistic regression (Lee, 2005; Chen and Wang, 2007; Mathew et al., 2007; Pradhan, 2010; Mousavi et al., 2011), multivariate statistical analysis models based on GIS and remote sensing techniques (Liu et al., 2004; Fourniadis et al., 2007; Lee and Choi, 2004; Manzo et al., 2012), and real-time debris flow hazard management for early warning (Jakob et al., 2012).

Debris flows are erosive and accumulative processes in drainage basins for which active tectonics is a very important factor in the determination of the topographical characteristics of the drainage basin (Keller 
and Pinter, 2002a, 2002b). The occurrence of a debris flow is mostly influenced by local topographical characteristics, active tectonics and rainfall (Maroukian et al., 2008). Although mainly controlled by tectonics (Mahmood and Gloaguen, 2012), the former two factors can provide the basis for occurrence of debris flows (Wadge, 1994; Anbalagan and Singh, 1996).

Geomorphic indices have been used to assess the cause and occurrence of debris flow hazards (Lee, 2005). El Hamdouni et al. (2008) used six indices to compute the IRAT along the southwestern border of the Sierra Nevada in southern Spain and classified four classes of tectonic activity. These researchers concluded that relatively high potentials of active tectonics are associated with the indicative values of the IRAT. Mahmood and Gloaguen (2012) used seven geomorphic indices to compute the IRAT using GIS at the Hindu Kush, Karakorum, and Himalayas ranges. The indicative values of the IRAT are consistent with known uplift rates, landform characteristics and geology. Gao et al. (2013) used geomorphic indices such as the hypsometric integral and the stream length gradient index to infer and evaluate the recent uplift of the northeastern margin of the Tibetan Plateau. HI spatially corresponds to the hanging walls of thrust faults and is positively correlated with the leveling data. Alipoor et al. (2011) assessed active tectonics using geomorphic indices around the Rudbar Lorestan dam site in the High Zagros Belt (SW of Iran). Thus, strong tectonics can produce landforms that may be favorable for debris flows.

Assessment of debris flow disasters often focuses on the regional/ macro scale, and most researchers choose large-scale drainage basins as study objects for which the practical significance of the assessment results should be addressed (Lee, 2005; Chen and Wang, 2007; Pradhan, 2010; Mousavi et al., 2011). In this study, we performed an analysis on a relatively large region that extends over the Beijing mountain area in China. The study discusses whether the susceptibility to a debris flow hazard can be evaluated with parameters used for evaluating active tectonics because topography of drainage basin created by rapid tectonics seems to be favorable for occurrence of debris flows. The method consists of extracting drainage basins from a DEM, calculating seven geomorphic indices, estimating IRAT, classifying IRAT levels, and determining the relationship between IRAT level and debris flow distribution in the drainage basin.

\section{Study area}

The Beijing municipality is located in the northwestern part of the North China Plain surrounded by the Yanshan Mountains to the north and west, and the Taihang Mountains in the northern section (Fig. 1). The mountainous area accounts for $62 \%$ of the entire region. The highest elevation is $2274 \mathrm{~m}$, with a general terrain declining from the northwest to the southeast. The mountains are high and steep with complex geological structures. Sandstone, limestone, schist, and clastic rocks of different geological ages are widely distributed in the area. In particular, the structure of the granite is coarse which makes it easily weathered into clay and sand that supplies the source material for debris flows.

The geomorphic setting in the Beijing mountain area is a result of complex interactions involving Yanshan neotectonic movements, and processes of erosion and deposition. The area contains a junction of two mountain ranges (Yanshan and Taihang Mountains). The Beijing mountain area experienced a strong neotectonic uplift, high rising and different tilting. These have created steep slopes, highly asymmetric valleys, elongated basins, V-shaped valleys, linearized drainages, active mountain fronts, high channel gradients, and high hypsometric integrals in the area (Zhong et al., 2004).

Main rivers in the study area are the Chaobai, Wenyu, and Yongding rivers. The region has a temperate semi-arid continental climate characterized by a cold dry winter, and a hot rainy summer. Average annual rainfall precipitation in the area is approximately $620 \mathrm{~mm}, 75-80 \%$ of which falls in the period from June to September, and concentrates

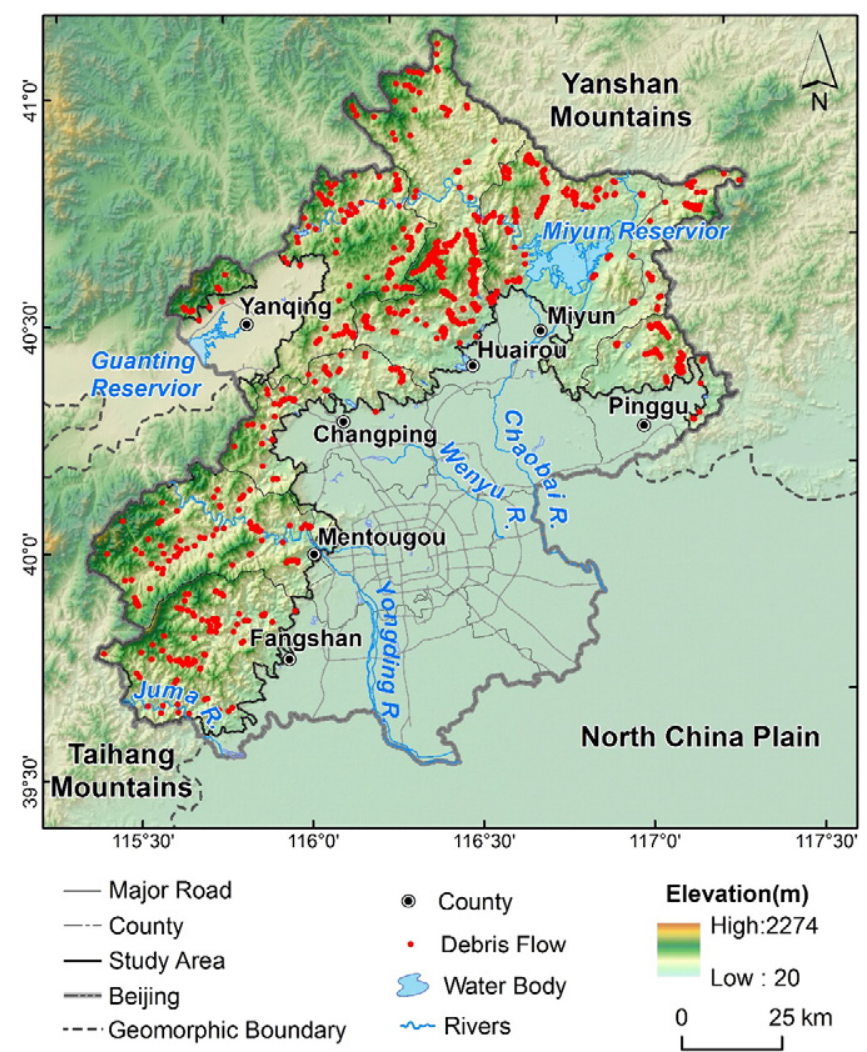

Fig. 1. Geographical setting of the study area.

especially in the period from late July to early August. Mentougou District and Huairou District are the two precipitation concentrated centers, resulting in a high occurrence probability of debris flow hazards (Zhong et al., 2004).

\section{Data sources}

The ASTER-DEM with a resolution of 30-m was used (Global Land Cover Facility, http://gdem.ersdac.jspacesystems.or.jp/), to extract drainage networks and drainage basins and calculate geomorphic indices using GIS techniques.

Based on field investigations, the 2.5-m ALOS images taken in 2010 and 2011, and the observation data reported in the debris flow in Beijing Mountain Area Project (Zhong et al., 2004), we visually interpreted and outlined 705 debris flow valleys in six districts including Huairou, Miyun, Yanqing, Mentougou, Pinggu, and Changping. The positions of debris flow valleys are indicated by their central points as shown in Fig. 1. Accordingly, the attributes of the debris flow valleys including length, area, slope, aspect, and erosive and accumulative characteristics can be calculated using GIS.

\section{Methods}

Geomorphic indices are useful indicators for evaluating the influence of active tectonics. Calculated from remote sensing data (DEM and satellite/aerial imagery) using GIS, these indices can be used as a reconnaissance to detect tectonic activity such as uplift, incision, erosion, and slip, and provide a basis for analyzing probability of natural hazard occurrence (Khan et al., 2013). This method can provide useful information in the Beijing mountain area, where limited quantitative analyses of active tectonics were conducted. 


\subsection{Workflow of debris flow hazard assessment}

In this study, the assessment of debris flow hazard was based on the drainage basins. First, drainage networks were extracted from the ASTER-DEM, and thereafter, drainage basins were obtained using the ArcGIS ArcHydro Toolbox. For each drainage basin, seven geomorphic indices were calculated including the relief amplitude $(R A)$, the hypsometric integral $(H I)$, the stream length gradient $(S L)$, the fractal dimension of drainage patterns $(F D)$, the basin shape index $\left(B_{S}\right)$, the asymmetry factor $(A F)$, and the ratio of valley floor width to height $\left(V_{\mathrm{f}}\right)$.

Next, a composite index, IRAT, which is the arithmetic mean of the seven geomorphic indices, was obtained to assess the relative level of tectonic activity. The number of debris flow valleys in each drainage basin was determined, and the IRAT value for each drainage basin was computed. The relationship between the IRAT class and the ratio of the number of the debris flows to the number of the drainage basins was obtained and analyzed, and the probable risk level was defined by the IRAT classes.

Finally, the drainage basins were divided into two categories based on the occurrence of debris flows. For drainage basins with debris flow records, the degree of hazard occurrence probability for each drainage basin was estimated based on the combined effect of the probable risk level and the occurrence frequency of the debris flows. Drainage basins without debris flow records were classified according to their probable risk levels (Fig. 2).

\subsection{Extraction of the drainage basins}

Drainage basins were extracted from the ASTER-DEM. We ranked the drainage networks in the Beijing mountain area into five classes

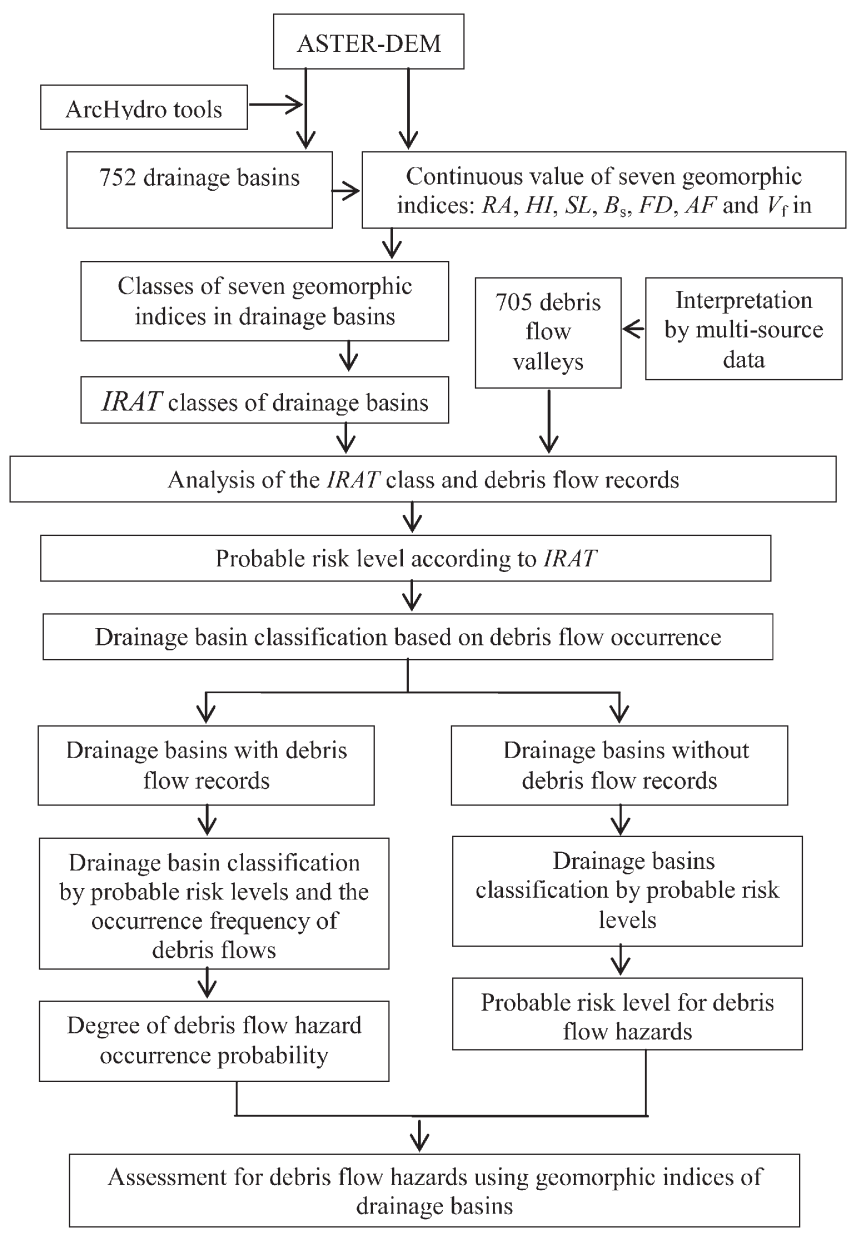

Fig. 2. Workflow of debris flow hazard assessment.
Table 1

Classification criterion of geomorphic indices representing active tectonics. RA: relief amplitude. $H I$ : hypsometric integral. SL: stream length gradient. FD: fractal dimension of drainage patterns. $B_{\mathrm{s}}$ : basin shape index. $A F$ : asymmetry factor. $V_{\mathrm{f}}$ : ratio of valley floor width to height.

\begin{tabular}{llllllll}
\hline Class & $R A$ & $H I$ & $S L$ & $F D$ & $B_{\mathrm{s}}$ & $|A F-50|$ & $V_{\mathrm{f}}$ \\
\hline 1 & $<70$ & $<0.3$ & $<25$ & $\geq 1.15$ & $<0.2$ & $<1$ & $\geq 5$ \\
2 & $70-200$ & $0.3-0.4$ & $25-75$ & $1.1-1.15$ & $0.2-0.4$ & $1-7.5$ & $2.5-5$ \\
3 & $200-500$ & $0.4-0.5$ & $75-200$ & $1.08-1.1$ & $0.4-0.8$ & $7.5-15$ & $1-2.5$ \\
4 & $500-1000$ & $0.5-0.6$ & $200-400$ & $1.06-1.08$ & $0.8-1.2$ & $15-30$ & $0.5-1$ \\
5 & $\geq 1000$ & $\mathrm{H} \geq 0.6$ & $\geq 400$ & $<1.06$ & $\geq 1.2$ & $\geq 30$ & $<0.5$ \\
\hline
\end{tabular}

using the Strahler ordering system and adjusted the drainage networks in reference to the river network at a 1:250,000 scale. In total, 752 drainage basins were extracted using the ArcHydro tools.

\subsection{Calculation of geomorphic indices}

The geomorphic indices represent a quantitative approach for various geomorphic features such as the river channel, the long profile, the valley morphology, and the tectonically derived landforms (El Hamdouni et al., 2008). We analyzed the above-noted seven geomorphic indices in the study area and assigned them to different tectonic classes according to the range of values and their geological meanings.

The seven indices were further grouped into four categories: 1 ) morphological index $(R A), 2)$ tectonic uplift indices (HI and $S L), 3)$ shape indices $\left(F D\right.$ and $\left.B_{\mathrm{s}}\right)$, and 4$)$ basin tilt indices $\left(A F\right.$ and $\left.V_{\mathrm{f}}\right)$.

\subsubsection{Morphological index}

$R A$ refers to the difference between the maximum and minimum elevations in an area such as a drainage basin (Whipple et al., 1999):

$R A=h_{\max }-h_{\min }$

where $h_{\max }$ and $h_{\min }$ are the maximum and minimum elevations (m) in a drainage basin, respectively.

$R A$ expresses the incision depth and the degree of surface denudation, which can be used to characterize the intensity of tectonic activity. Based on the digital geomorphic classification standards of China (Cheng et al., 2011), $R A$ was classified into five classes: Class 1 $(R A<70 \mathrm{~m}), 2(70 \mathrm{~m} \leq R A<200 \mathrm{~m}), 3(200 \mathrm{~m} \leq R A<500 \mathrm{~m}), 4$ $(500 \mathrm{~m} \leq R A<1000 \mathrm{~m})$, and $5(R A \geq 1000 \mathrm{~m})$ (Table 1$)$.

\subsubsection{Tectonic uplift indices}

$\mathrm{HI}$ is typically derived for a particular drainage basin as an index independent of the basin area. HI explains the distribution of elevations in a given landscape area, particularly a drainage basin (Strahler, 1952). The index is defined as the area below the hypsometric curve: thus it reflects the volume of a basin that has not been eroded. $\mathrm{HI}$ is approximated as (Pike and Wilson, 1971):

$H I=\frac{h_{\text {mean }}-h_{\text {min }}}{h_{\max }-\mathrm{h}_{\min }}$

where $h_{\text {mean }}$ is the mean elevation (m) of a drainage basin.

\section{Table 2}

Number of the drainage basins for each class of the geomorphic indices. $R A$ : relief amplitude. HI: hypsometric integral. SL: stream length gradient. FD: fractal dimension of drainage patterns. $B_{\mathrm{s}}$ : basin shape index. $A F$ : asymmetry factor. $V_{\mathrm{f}}$ : ratio of valley floor width to height.

\begin{tabular}{lrrrrrrl}
\hline Class & \multicolumn{1}{c}{$R A$} & \multicolumn{1}{c}{$H I$} & \multicolumn{1}{c}{$S L$} & \multicolumn{1}{c}{$F D$} & \multicolumn{1}{c}{$B_{\mathrm{s}}$} & $|A F-50|$ & $V_{\mathrm{f}}$ \\
\hline 1 & 9 & 50 & 170 & 17 & 4 & 25 & 102 \\
2 & 32 & 21 & 136 & 62 & 40 & 302 & 101 \\
3 & 177 & 38 & 203 & 80 & 194 & 213 & 171 \\
4 & 450 & 185 & 157 & 150 & 192 & 195 & 160 \\
5 & 84 & 458 & 86 & 443 & 322 & 17 & 218 \\
\hline
\end{tabular}


High $H I$ values may suggest a younger landscape, possibly produced by active tectonics and generally corresponding to cases where majority of uplands have not been eroded. A high $H I$ value could also result from a recent incision for a young geomorphic surface formed by deposition. Low values are related to older landscapes that have been significantly eroded and less impacted by recent active tectonics (Mahmood and Gloaguen, 2012). From the concept of the Davisian erosion cycle theory (Davis, 1899), the $H I$ values were divided into five classes: Class 1 ( $H I<0.3), 2(0.3 \leq H I<0.4), 3(0.4 \leq H I<0.5), 4(0.5 \leq H I<0.6)$, and 5 $(H I \geq 0.6)$. The classification results are shown in Table 1.

SL was defined by Hack (1973) to assess the influence of environmental variables on longitudinal stream profiles and to test whether

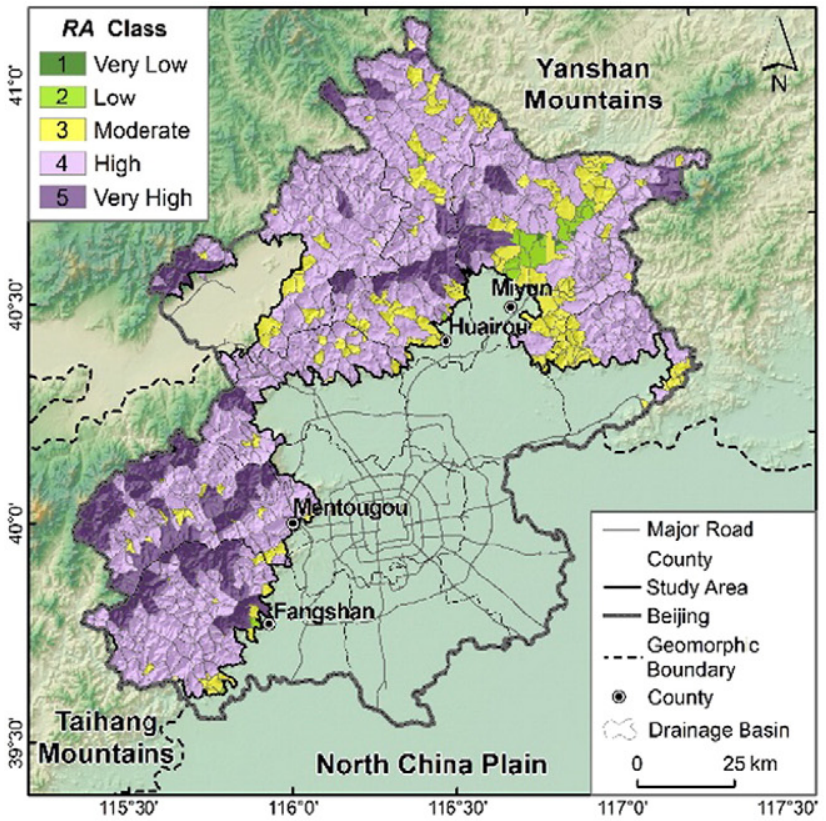

a)

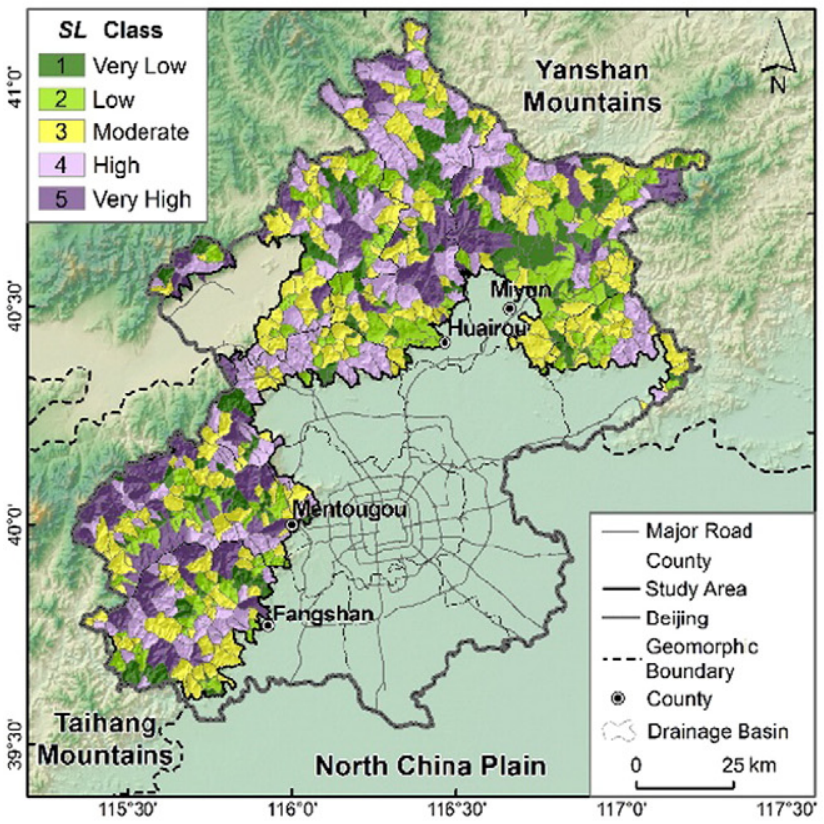

c) streams had reached equilibrium. SL is an indicator to measure changes in a river profile, and in particular, it is very sensitive to changes in the river slope. Changes in SL are mainly influenced by tectonic activity, rock resistance to erosion, topographic characteristics and climatic factors (Hack, 1973). On the one hand, changes in the river gradient caused by local tectonic activities will increase the value of SL. On the other hand, flow through rock with strongly resistant to erosion and longterm differences in the erosion of adjacent regions will also steepen the river slope lead to an increased value of $S L$. The $S L$ is computed using the equation:

$S L=(\Delta H / \Delta L) L$

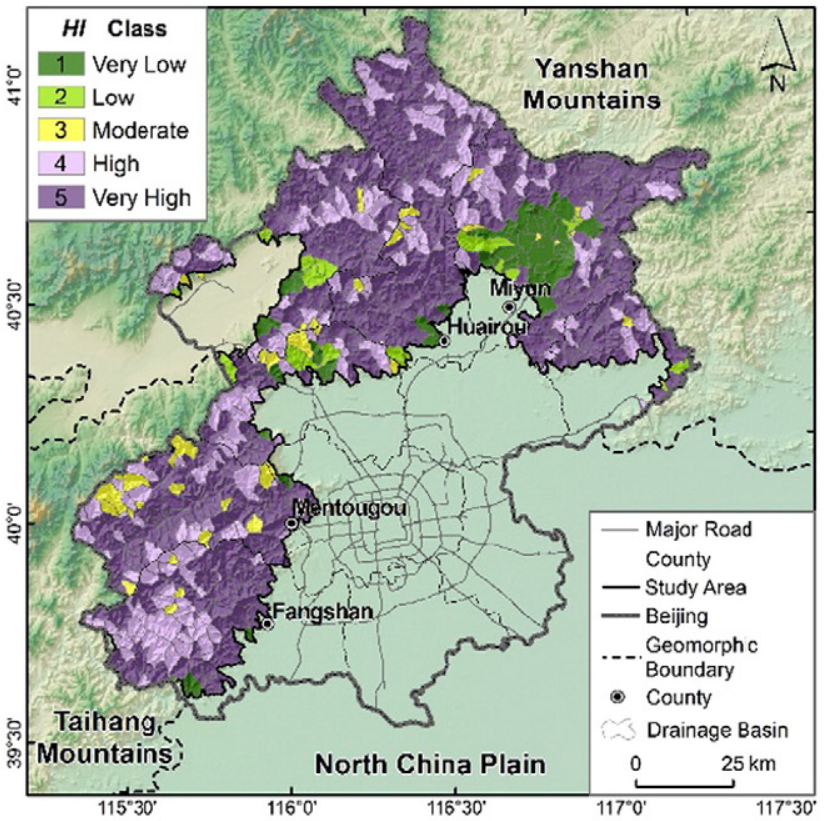

b)

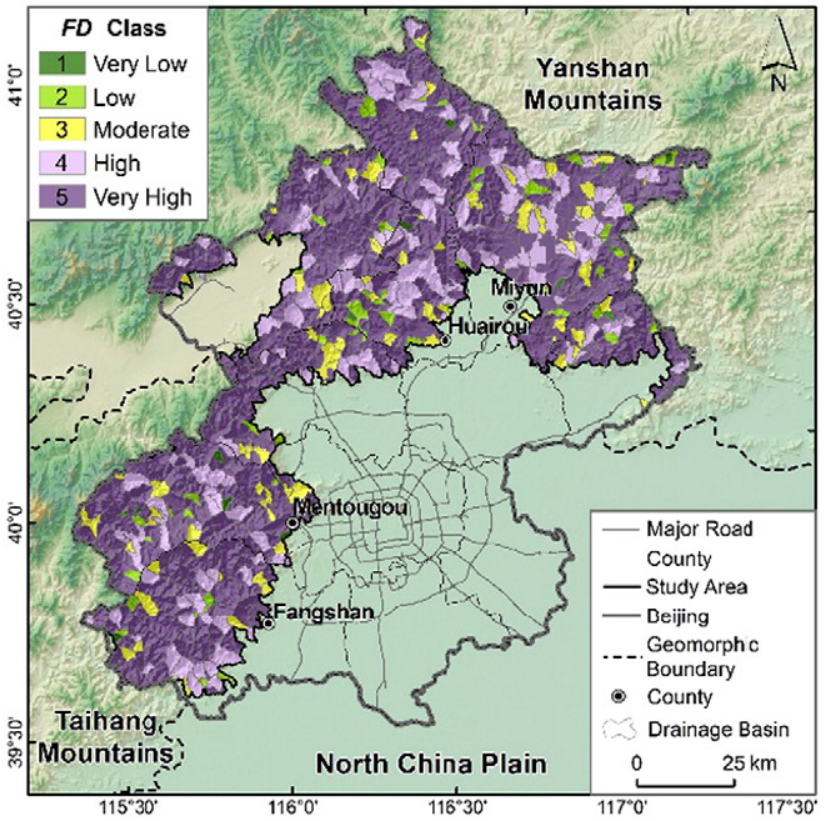

d)

Fig. 3. Distribution of numerical classes of seven geomorphology indices for drainage basins. a) $R A$; b) $H I$; c) $S L$; d) $F D$; e) $B_{\mathrm{s}}$; f) $A F$; g) $V_{\mathrm{f}}$. 


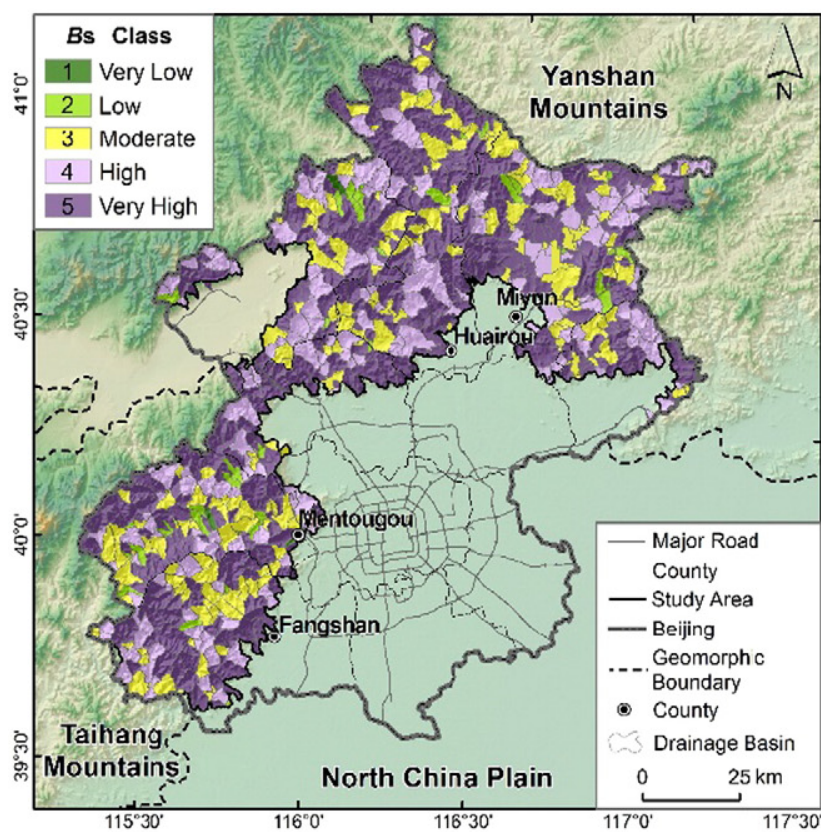

e)

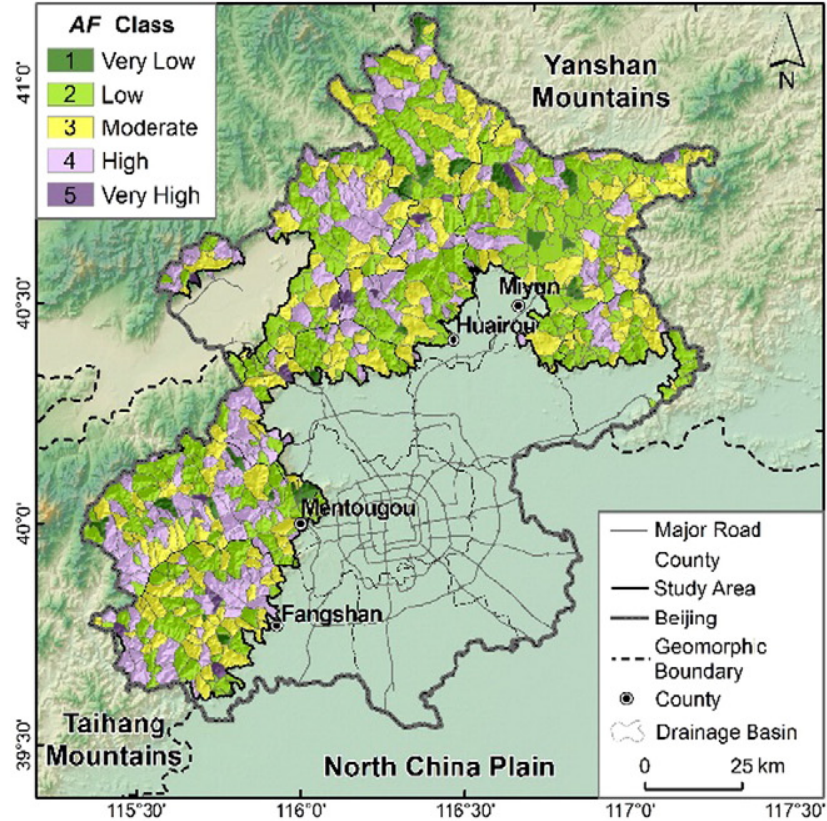

f)

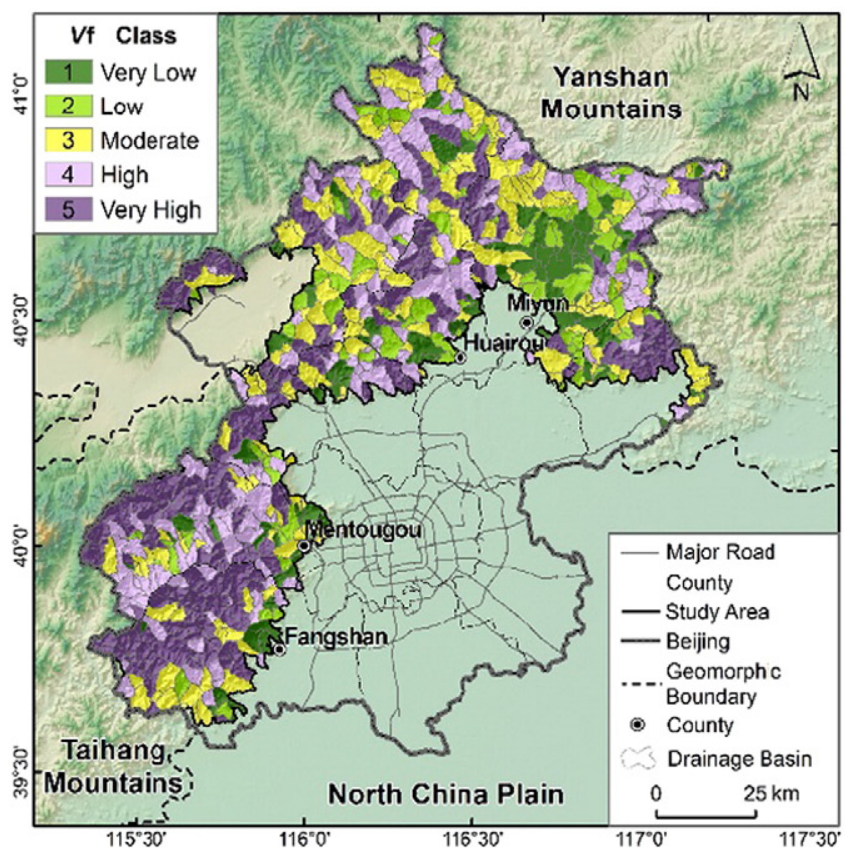

g)

Fig. 3 (continued).

where $\Delta H$ is the change in elevation (m), $\Delta L$ is the length of reach (m), and $L$ is the horizontal length $(\mathrm{m})$ from the drainage divide to the midpoint of the reach.

The value of $S L$ was computed along the streams and rivers by drawing the "Hack profile" of each sub-basin and using Microsoft Excel to fit linear regression lines. The slope of the regression line corresponds to the $S L$ index. The $S L$ values in this paper were grouped into five classes based on Hack (1973): Class $1(S L<25), 2$ (25 $\leq S L<75), 3$ ( $75 \leq S L<200), 4(200 \leq S L<400)$ and $5(S L \geq 400)$ (Table 1$)$.

\subsubsection{Shape indices}

$F D$ is defined as a shape that in some way comprises parts similar to the whole (Guillermo et al., 2004; Dombradi et al., 2007; Gloaguen et al., 2007). The degree of complexity in a drainage network can be reflected by FD because the structure of the feature has characteristics of invariability of scale and self-similarity.

The box-counting method using a moving box of variable size was implemented on a binary image of the DEM-derived drainage network. This method interprets black drainage patterns as 1 and empty white 
space as 0 , and counts the number of drainage pixels within the box (Skubalska-Rafajlowicz, 2005). FD is calculated as:

$F D=\lim _{S \rightarrow 0} \frac{\log N(S)}{\log (1 / S)}$

where $N(S)$ is the number of boxes and $S$ is the length of the box (m). The slope of the best fit line for a $\log -\log$ plot of $N(S)$ and $1 / S$ is equal to $F D$.

The $F D$ values were divided into five classes based on Guillermo et al. (2004): Class 1 ( $F D \geq 1.15), 2$ ( $1.1 \leq F D<1.15), 3$ ( $1.08 \leq F D<1.1), 4$ $(1.06 \leq F D<1.08)$, and $5(F D<1.06)$ (Table 1$)$.

$B_{\mathrm{S}}$ represents the horizontal projection of a basin (Ramirez-Herrera, 1998), which is expressed as:

$B_{\mathrm{s}}=\frac{L_{\mathrm{b}}}{W_{\mathrm{b}}}$

where $L_{\mathrm{b}}$ is the length of a basin (m) measured from the headwaters to the mouth and $W_{\mathrm{b}}$ is the width of a basin $(\mathrm{m})$ measured at its widest cross section.

The $B_{\mathrm{S}}$ index can reflect the degree of active tectonic uplift. Normally, a high value of $B_{\mathrm{s}}$ indicates a long and narrow drainage basin, for which the potential of tectonic activity is high. A low value reflects a nearly round basin and tectonic activity is weak (El Hamdouni et al., 2008). The values of the $B_{\mathrm{s}}$ index are divided into five categories according to Ramirez-Herrera (1998): Class $1\left(B_{\mathrm{s}}<0.2\right), 2\left(0.2 \leq B_{\mathrm{s}}<0.4\right), 3$ $\left(0.4 \leq B_{\mathrm{s}}<0.8\right), 4\left(0.8 \leq B_{\mathrm{s}}<1.2\right)$ and $5\left(B_{\mathrm{s}} \geq 1.2\right)$ (Table 1$)$.

\subsubsection{Basin tilt indices}

$A F$ is used for evaluating the tectonic tilting on a drainage basin scale (Hare and Gardner, 1985), and is sensitive to changes in inclination perpendicular to the flow direction. The method can be applied in a relatively large area. $A F$ is defined as:

$A F=\left(A_{\mathrm{r}} / A_{\mathrm{t}}\right) \times 100$

where $A_{\mathrm{r}}$ is the area $\left(\mathrm{km}^{2}\right)$ of the basin on the right (looking downstream) of the main stream and $A_{\mathrm{t}}$ is the total area $\left(\mathrm{km}^{2}\right)$ of the drainage basin.

$A F$ has a threshold value of 50 , which affects the active tectonics/lithological control or differential erosion (El Hamdouni et al., 2008). When the value of $A F$ is about 50, the basin is in a stable state with little or no tilt. When the value of $A F$ is markedly greater or less than 50 , the basin may be tilted, although geological conditions, such as changes in lithological structure may also cause such asymmetry.

The $|A F-50|$ value was calculated and then divided into five classes according to Hare and Gardner (1985): Class $1(|A F-50|<1), 2$ $(1 \leq|A F-50|<7.5), 3(7.5 \leq|A F-50|<15), 4(15 \leq|A F-50|<30)$ and 5 $(|A F-50| \geq 30)$ (Table 1$)$.

$V_{\mathrm{f}}$ is a geomorphic index that distinguishes between $\mathrm{V}$-shaped and U-shaped valleys (Bull and McFadden, 1977). $V_{\mathrm{f}}$ is defined as:

$V_{\mathrm{f}}=\frac{2 W_{\mathrm{vf}}}{\left(E_{\mathrm{ld}}-E_{\mathrm{sc}}\right)+\left(E_{\mathrm{rd}}-E_{\mathrm{sc}}\right)}$

where $W_{\mathrm{vf}}$ is the width of the valley floor $(\mathrm{m}), E_{\mathrm{ld}}$ and $E_{\mathrm{rd}}$ are the elevation ( $\mathrm{m}$ ) of the left- and right-hand valley divides (facing downstream), respectively, and $E_{\mathrm{sc}}$ is the elevation of the valley floor $(\mathrm{m})$.

$V_{\mathrm{f}}$ can reflect the level of tectonic activity: low values are associated with faster uplift and erosion and high values are with lower uplift rates. Different types of river valleys have different $V_{f}$ values. Generally, $\mathrm{V}$-shaped valleys have relatively low values of $V_{\mathrm{f}}$ whereas U-shaped valleys have relatively high values.

The $V_{\mathrm{f}}$ values were divided into five classes based on Bull and McFadden (1977): Class $1\left(V_{\mathrm{f}} \geq 5\right), 2\left(2.5 \leq V_{\mathrm{f}}<5\right), 3\left(1 \leq V_{\mathrm{f}}<2.5\right), 4$ $\left(0.5 \leq V_{\mathrm{f}}<1\right)$ and $5\left(V_{\mathrm{f}}<0.5\right)$ (Table 1$)$
Table 3

Ratio of the number of debris flow valleys to the number of the drainage basins for each class of the geomorphic indices. RA: relief amplitude. HI: hypsometric integral. SL: stream length gradient. $F D$ : fractal dimension of drainage patterns. $B_{\mathrm{s}}$ : basin shape index. $A F$ : asymmetry factor. $V_{\mathrm{f}}$ : ratio of valley floor width to height.

\begin{tabular}{llllllll}
\hline Class & $R A$ & $H I$ & $S L$ & $F D$ & $B_{\mathrm{s}}$ & $|A F-50|$ & $V_{\mathrm{f}}$ \\
\hline 1 & 0 & 0.30 & 0.48 & 0.29 & 0.25 & 0.56 & 0.36 \\
2 & 0.03 & 0.48 & 0.63 & 0.42 & 0.70 & 0.86 & 0.46 \\
3 & 0.19 & 0.58 & 1.01 & 0.58 & 0.82 & 0.88 & 1.00 \\
4 & 1.17 & 0.91 & 1.23 & 0.89 & 0.97 & 1.05 & 1.14 \\
5 & 1.73 & 1.07 & 1.63 & 1.12 & 1.02 & 2.24 & 1.23 \\
\hline
\end{tabular}

\subsection{Calculation of IRAT}

Some previous studies used a combination of two or more geomorphological indices to obtain semi-quantitative information regarding the relative tectonic activity of a mountain range (Bull and McFadden, 1977; Silva et al., 2003; El Hamdouni et al., 2008). The use of the seven geomorphic indices mentioned above, as well as IRAT, exhibits tectonic activity zones in the study area. We have summarized the classification criteria from previous research results (Strahler, 1952; Bull and McFadden, 1977; Molnar and England, 1990; Silva et al., 2003; Dehbozorgi et al., 2010). Based on the 705 debris flow valleys within the Beijing mountain area and the geomorphic significance of the seven geomorphic indices, the classification criteria for each geomorphic index was redefined (Table 1). To obtain more precise results, the seven indices were divided into five classes, and each class was assigned a weighting value. These classes were then summed and averaged to obtain an IRAT over the entire study area. IRAT is defined as:

$I R A T=\left(R A+\mathrm{HI}+\mathrm{SL}+\mathrm{FD}+B_{\mathrm{S}}+A F+V_{\mathrm{f}}\right) / 7$

Such an arithmetic mean has been found useful in differentiating tectonically active areas (El Hamdouni et al., 2008; Dehbozorgi et al., 2010; Mahmood and Gloaguen, 2012).

\section{Results}

\subsection{Geomorphic indices}

\subsubsection{RA}

The $R A$ values in the study area range from 8 to $1475 \mathrm{~m}$, with a mean of $661 \mathrm{~m}$. The drainage basin numbers for each $R A$ class is shown in Table 2 . Class 5 covers the largest area in the basin ( $60 \%$ of the entire basin) followed by Class 3 (24\%) and Class 4 (11\%).

The distribution of $R A$ classes in the study area is shown in Fig. 3(a). Class 5 is mainly distributed in the steep slope area of the mountains, which are characterized by less vegetation coverage due to relatively frequent anthropogenic activities. Class 4 is mainly distributed in the inter-mountain area with dense land cover and relatively few anthropogenic activities. Class 3 is primarily distributed in low and gentle hilly areas.

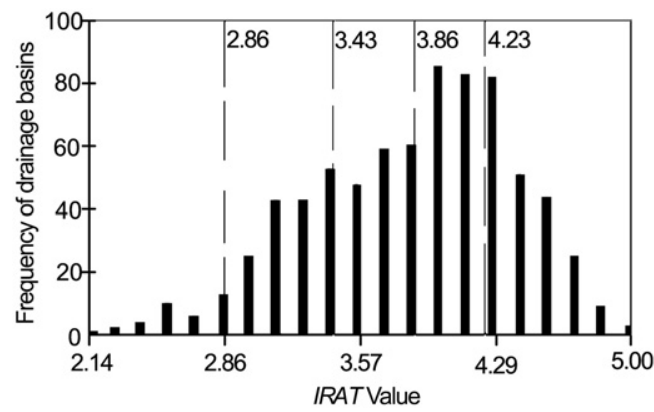

Fig. 4. Frequency distribution of the IRAT values. 
Table 4

Numbers and ratios of drainage basins and debris flow valleys for different IRAT classes.

\begin{tabular}{llccl}
\hline Class & Value & $\begin{array}{l}\text { Drainage } \\
\text { basins }\end{array}$ & $\begin{array}{l}\text { Debris-flow } \\
\text { valleys }\end{array}$ & $\begin{array}{l}\text { Debris-flow to } \\
\text { drainage basin ratio }\end{array}$ \\
\hline 1 & $<2.86$ & 36 & 3 & 0.08 \\
2 & $2.86-3.43$ & 164 & 56 & 0.34 \\
3 & $3.43-3.86$ & 167 & 129 & 0.77 \\
4 & $3.86-4.23$ & 171 & 185 & 1.08 \\
5 & $\geq 4.23$ & 214 & 332 & 1.55 \\
\hline
\end{tabular}

\subsection{2. $\mathrm{HI}$}

The $H I$ values in the study area range from 0.05 to 0.89 . The drainage basin numbers for each $\mathrm{HI}$ class (Table 2 ) shows that $61 \%$ of the drainage basins have $H I$ higher than 0.6 . Drainage basins with $H I$ between 0.5 and 0.6 are $24.6 \%$, and $H I$ between 0.4 and 0.6 are $5.1 \%$ of the total area. Drainage basins with $\mathrm{HI}$ below 0.4 are only $9.4 \%$ of the basins.

The distribution of $\mathrm{HI}$ classes is shown in Fig. 3b. Classes 4 and 5 are primarily distributed in the inter-mountain area with high to medium relief, steep slope gradients and dense vegetation.

\subsection{3. $S L$}

The number of the drainage basins with SL values higher than 500 accounts for $6.4 \%$ of the total area. The drainage basin numbers for each SL class is listed in Table 2. Each SL class is almost evenly distributed in terms of the number of basins.

The distribution of SL classes in the study area is shown in Fig. 3c. The drainage basins in the upper reaches of the Yongding, Chaobai and Wenyu rivers have higher $S L$ values, whereas those areas around the Miyun Reservoir have lower $S L$ values.

\subsubsection{FD}

The highest value of $F D$ within the study area is 1.246 . The number of drainage basins for each FD class is described in Table 2. Class 5 covers the largest area in the basins (59\%), followed by Class 4 (20\%). The highest class has an FD value close to 1, indicating a low FD state of the drainage basin.

Fig. 3d shows the distribution of FD classes in the study area. The primary two FD classes are Classes 4 and 5. Class 3 is distributed only sparsely.

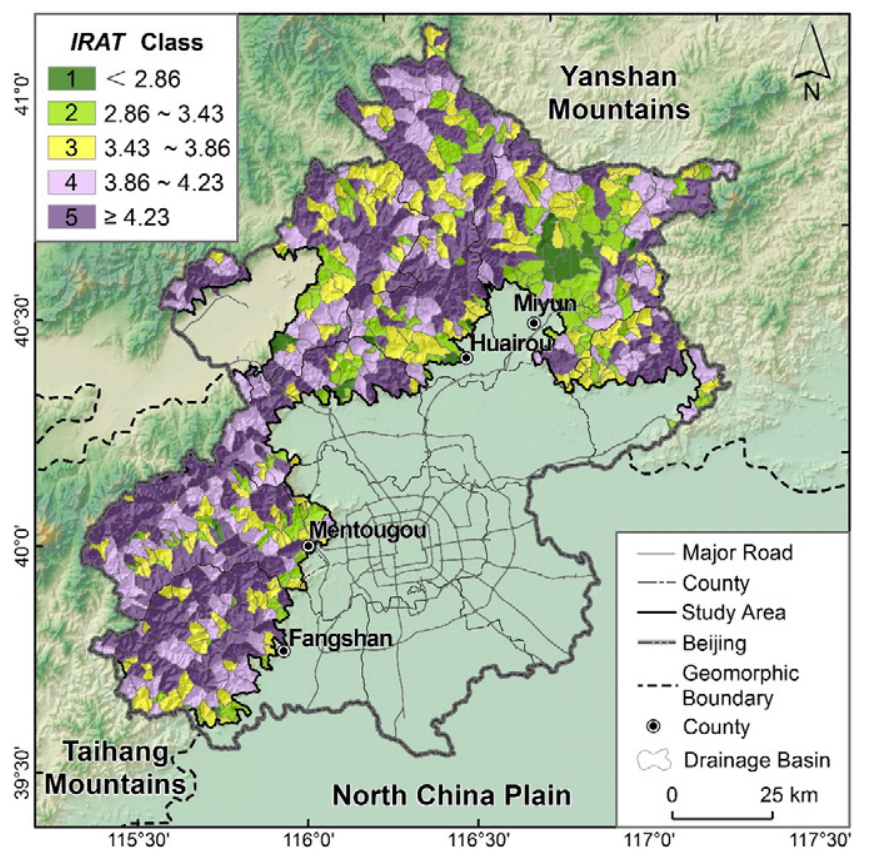

Fig. 5. Distribution of IRAT classes for drainage basins.
Table 5

Number of debris flow drainage basins (left side of slash) and degree of the hazard occurrence probability (right side) at different frequencies and probable risk levels.

\begin{tabular}{lllcrl}
\hline \multirow{2}{*}{ Frequency } & \multicolumn{4}{l}{ Probable risk level } \\
\cline { 2 - 6 } & Very low & Low & Moderate & High & Very high \\
\hline$\geq 6$ & 0 & 0 & $2 / 3$ & $6 / 4$ & $17 / 5$ \\
$3-5$ & 0 & $6 / 2$ & $13 / 3$ & $15 / 4$ & $17 / 5$ \\
2 & 0 & $7 / 1$ & $18 / 2$ & $18 / 3$ & $21 / 4$ \\
1 & $3 / 1$ & $22 / 1$ & $31 / 2$ & $44 / 3$ & $48 / 4$ \\
\hline
\end{tabular}

\subsection{5. $B_{s}$}

The number of drainage basins for each $B_{\mathrm{s}}$ class is listed in Table 2 . The primarily $B_{\mathrm{s}}$ class is Class 5 (43\%), followed by Classes 4 (23\%) and $3(23 \%)$.

The distribution of $B_{\mathrm{S}}$ classes in the study area is shown in Fig. 3(e). The three main classes (5, 4 and 3 ) are primarily distributed in the kernel area of the mountain. Most drainage basins are along the flow direction, indicating that these drainage basins deviate from the steady status.

\subsection{6. $A F$}

The number of drainage basins for each $A F$ class is listed in Table 2. The primarily $A F$ class is Class 2 (40\%), followed by Classes $3(28 \%)$ and 4 (26\%).

The distribution of $A F$ classes is shown in Fig. 3f. Classes 1 and 5 are sparsely distributed, while Class 2 is widely distributed, indicating that the drainage basins have nearly symmetrical shapes.

\subsection{7. $V_{f}$}

The $V_{\mathrm{f}}$ values in the study area range from 0.08 to 59.51 . The number of drainage basins for each $V_{\mathrm{f}}$ class is shown in Table 2, and the distribution of the $V_{\mathrm{f}}$ classes is shown in Fig. $3 \mathrm{~g}$. Classes 4 and 5 are mainly distributed in the southwestern Fangshan District and Mentougou District, while lower classes are primarily distributed around the Miyun reservoir.

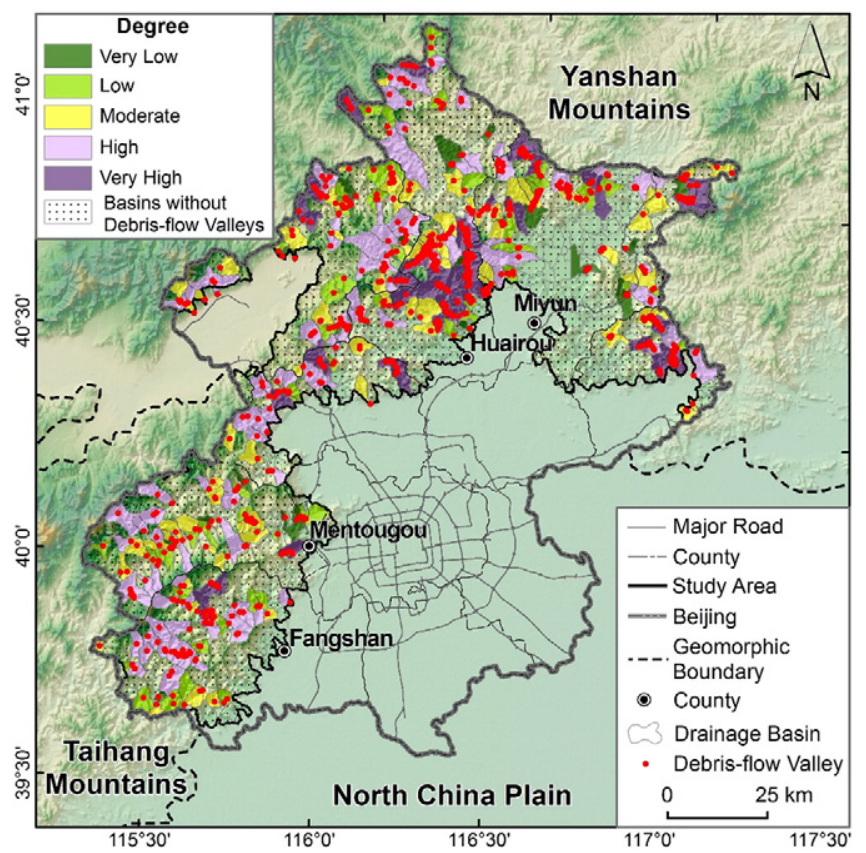

Fig. 6. Degree of debris flow hazard occurrence probability for drainage basins. 


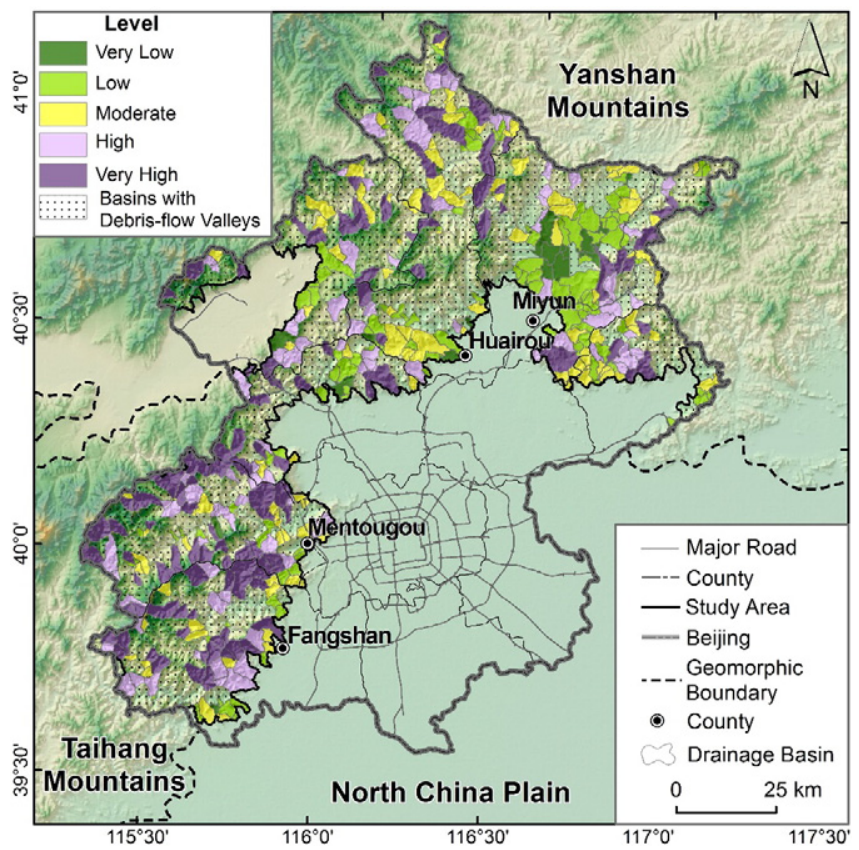

Fig. 7. Distribution of probable risk levels for no debris flows drainage basins.

\subsection{IRAT}

The ratio of the number of the debris flow valleys to drainage basins for each geomorphic index (Table 3 ) shows that the ratio increases along with the increase of class. To use the geomorphic indices comprehensively, the IRAT value was computed based on Eq. (8) (Fig. 4). The IRAT values have a right-skewed tendency, indicating that the study area had a relatively strong neotectonic processes during the Quaternary (Zhong et al., 2004).

The IRAT values range from 2.14 to 5.00 with a mean of 3.86 and standard deviation of 0.54 indicating relatively active tectonics. The

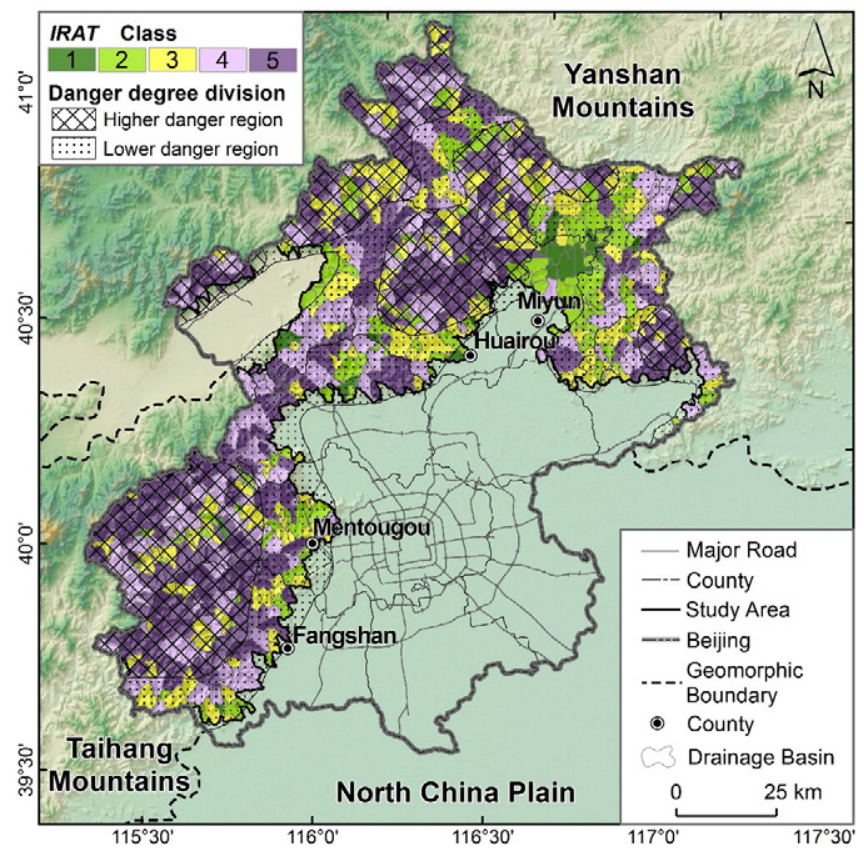

Fig. 8. Comparison between the IRAT classes from this research and the danger degree divisions from Zhong et al. (2004). relatively low standard deviation reflects that tectonic activities do not vary significantly over the study area.

Based on IRAT, the 752 drainage basins in the study area were divided into five classes using the natural breaks method in ArcGIS: Class 1 with $I R A T<2.86,2$ with $2.86 \leq I R A T<3.43,3$ with $3.43 \leq I R A T<3.86,4$ with $3.86 \leq I R A T<4.23$, and 5 with $I R A T \geq 4.23$ (Table 4, Fig. 5). Class 5 has 214 drainage basins and 332 debris flow valleys, and approximately 1.55 debris flow valleys per drainage basin. For the lower classes, the number and relative frequency of debris flow valleys evidently decrease.

High IRAT values occur in the middle mountain areas of the northern Huairou District and the southwestern Mentougou District having steep slopes, high to medium relief, severe erosion, and dense faults. The moderate class is mainly distributed in the margin of the mountain area in the Fangshan and Huairou Districts having medium to low relief, slightly tilted slopes, sparse vegetation and intensive human activity. The lower class is primarily distributed around the Miyun reservoir, which lies on the boundary between mountains and plains, and has gentle slopes, low relief, and fewer faults.

\subsection{Assessment of debris flow hazard probability}

The IRAT classes have a close relationship with the occurrence probability of debris flows (Table 4). In the study area, 288 drainage basins have records of debris flow events. Therefore, the drainage basins can be divided into two types: debris flow drainage basins and non-debris flow drainage basins. We made assessment for each type.

\subsubsection{Assessment of debris flow drainage basins}

The drainage basins in which debris flows have occurred were divided into four classes based on the frequency of debris flows: high frequency ( $\geq 6$ ), medium (3-5), low (2), and very low (1) (Table 5).

In Table 5, among all the 288 debris flow drainage basins, about $65 \%$ are distributed in the high and very high degrees of probable risk level. The degree of the debris flow hazard occurrence probability increases along with the increase in the probable risk level.

The distribution of the degree of the debris flow hazard occurrence probability is shown in Fig. 6. The degree of the debris flow hazard occurrence probability is generally high all over the drainage basins. Areas with much higher probability degrees are primarily distributed in the northern Huairou District and the margin area.

\subsubsection{Assessment of no debris flow drainage basins}

The drainage basins in which debris flows did not occur were divided into five classes based on the probable risk level. The number of the no debris flow drainage basins at the probable risk levels of very low, low, moderate, high and very high is $33,129,103,88$ and 111 , respectively. Of the 464 no debris flow drainage basins, approximately $43 \%$ (199) are distributed at the high and very high risk levels.

The distribution of no debris flow drainage basins at different probable risk levels is shown in Fig. 7. The high level region is mainly distributed in southwestern mountain area of the Mentougou and Fangshan Districts, and the low level region is mainly distributed in the northeastern area around the Miyun reservoir.

\section{Discussion}

Zhong et al. (2004) used relative elevation as the topographic index, the synthesized status of the fault and stratum as the geological index, and the rainfall volume from June to September as the rainfall index. Based on the values of these indices, Zhong et al. (2004) identified zones of different dangerous degrees of debris flows hazards in the Beijing area: higher danger zones, lower danger zones and nondanger zones. Fig. 8 shows the distribution of the three zones and the IRAT values. The higher danger zones are mainly distributed in the northern and western middle-relief mountainous areas, and the zones 
include 588 debris flow valleys. The regions with IRATClasses 4 and 5 include 517 debris flow valleys. The coincidence degree of the two results is $>85 \%$. This high coincidence confirms that IRAT can well represent the levels of debris flow hazards.

The magnitude of a debris flow hazard is affected by many factors. Therefore, Zhong et al. (2004) considered not only topography but also rainfall and lithology. However, geomorphic analysis is an essential basis for evaluating the occurrence of debris flow hazards (Glade, 2005). For example, on the south flank of the Santa Ynez Range in southern California, USA, the morphologic conditions of drainage systems have provided channels dominated by debris flows (Keller et al., 2015). Although the geomorphic conditions representing tectonic activities cannot fully confirm the occurrence of debris flows, they may indicate drainage basins highly prone to hydro-geomorphic hazards including debris flows (Khan et al., 2013).

\section{Conclusions}

Using a 30-m-resolution DEM, 752 drainage basins were extracted in the Beijing mountain area and seven geomorphic indices for the basins were computed. The IRAT value was computed as the arithmetic mean of the seven indices. IRAT is an indicator of the intensity of active tectonics. We also identified valleys where debris flows occurred, and compared the number of the debris flow valleys and the number of drainage basins and with different classes of IRAT. The ratio increases with the increase of the class.

Drainage basins with higher IRAT values also correspond well to the higher danger zones of debris flows identified by Zhong et al. (2004). Moreover, such basins often have records of past debris flow events. These results indicate that the geomorphic conditions provided by tectonic activity are important basis for debris flow hazards, although other factors also affect the occurrence of debris flows.

\section{Acknowledgments}

This research was supported by the National Mountain Flood Disaster Investigation Project (SHZH-IWHR-57), Surveying and Mapping Geoinformation Nonprofit Specific Project (201512033), the Major State Basic Research Development Program of China (2015CB954101), the National Natural Science Foundation of China (41171332, 41301469), the National Science Technology Basic Special Project (2011FY110400-2). We thank Professor Yongbo Liu in the University of Guelph for checking and revising the language, and the editor (Professor Takashi Oguchi) and anonymous reviewers for their labor and precious time for improving our manuscript.

\section{References}

Alipoor, R., Poorkermani, M., Zare, M., El Hamdouni, R., 2011. Active tectonic assessment around Rudbar Lorestan dam site, High Zagros Belt (SW of Iran). Geomorphology 128, 1-14.

Anbalagan, R., Singh, B., 1996. Landslide hazard and risk assessment mapping of mountainous terrains: a case study from Kumaun Himalaya India. Eng. Geol. 43, 237-246.

Bull, W.B., McFadden, L.D., 1977. Tectonic geomorphology north and south of the Garlock fault, California. In: Doehring, D.O. (Ed.), Geomorphology in Arid Regions. Proceedings of the Eighth Annual Geomorphology Symposium. State University of New York, Binghamton, pp. 115-138.

Carrara, A., 1991. GIS techniques and statistical models in evaluating landslide hazard. Earth Surf. Process. Landf. 16, 427-445.

Chen, Z.H., Wang, J.F., 2007. Landslide hazard mapping using logistic regression model in Mackenzie Valley, Canada. Nat. Hazards 42, 75-89.

Cheng, W.M., Zhou, C.H., Li, B.Y., Zhang, B.P., 2011. Structure and contents of layered classification system of digital geomorphology for China. J. Geogr. Sci. 21, 771-790.

Davis, W.M., 1899. The geographical cycle. Geogr. J. 14, 481-504.

Dehbozorgi, M., Pourkermani, M., Arian, M., Matkan, A.A., Motamedi, H., Hosseiniasl, A 2010. Quantitative analysis of relative tectonic activity in the Sarvestan area, central Zagros, Iran. Geomorphology 121, 329-341.

Dombradi, E., Timar, G., Gabor, B., Sierd, C., Frank, H., 2007. Fractal dimension estimations of drainage network in the Carpathiane-Pannonian system. Glob. Planet. Chang. 58, $197-213$.
El Hamdouni, R., Irigaray, C., Fernandez, T., Chacon, J., Keller, E.A., 2008. Assessment of relative active tectonics, southwest border of Sierra Nevada (Southern Spain). Geomorphology 96, 150-173.

Fourniadis, I.G., Liu, J.G., Mason, P.J., 2007. Landsat hazard assessment in the Three Gorges area, China, using ASTER imagery: Wushan-Badong. Geomorphology 84, 126-144.

Gao, M.X., Zeilinger, G., Xu, X.W., Wang, Q.L., Hao, M., 2013. DEM and GIS analysis of geomorphic indices for evaluating recent uplift of the northeastern margin of the Tibetan Plateau, China. Geomorphology 190, 61-72.

Glade, T., 2005. Linking debris-flow hazard assessments with geomorphology. Geomorphology 66, 189-213.

Gloaguen, R., Marpu, P.R., Niemeyer, I., 2007. Automatic extraction of faults and fractal analysis from remote sensing data. Nonlinear Process. Geophys. 14, 131-138.

Guillermo, R.A., Gerardo, M.E.P., Piccoloa, M.C., Pierini, J., 2004. Fractal analysis of tida channels in the Bahia Blanca Estuary (Argentina). Geomorphology 57, 263-274.

Guzzetti, F., 2000. Landslide fatalities and the evaluation of landslide risk in Italy. Eng. Geol. 58, 89-107.

Hack, J.T., 1973. Stream-profiles analysis and stream-gradient index. Journal of Research of the U.S. Geophys. Surv. 1, 421-429.

Hare, P.H., Gardner, T.W., 1985. Geomorphic indicators of vertical neotectonism along converging plate margins, Nicoya Peninsula, Costa Rica. In: Morisawa, M., Hack, J.T. (Eds.), Tectonic Geomorphology. Allen and Unwin, Boston, pp. 75-104.

Hewitt, K., 1998. Catastrophic landslides and their effects on the Upper Indus streams, Karakoram Himalaya, northern Pakistan. Geomorphology 26, 47-80.

Iverson, R.M., 1997. The physics of debris flows. Rev. Geophys. 35, 245-296.

Jakob, M., Owen, T., Simpson, T., 2012. A regional real-time debris-flow warning system for the District of North Vancouver, Canada. Landslides 9, 165-178.

Keller, E.A., Pinter, N., 2002a. Active Tectonics: Earthquakes, Uplift and Landscape. second ed. Prentice Hall, NJ (362 pp.).

Keller, E.A., Pinter, N., 2002b. Active Tectonics: Earthquakes, Uplift, and Landscape. Prentice Hall, New Jersey.

Keller, E.A., Bean, G., Best, D., 2015. Fluvial geomorphology of a boulder-bed, debris-flow dominated channel in an active tectonic environment. Geomorphology 243, 14-26.

Khan, M.A., Haneefb, M., Khana, A.S., Tahirkheli, T., 2013. Debris-flow hazards on tributary junction fans, Chitral, Hindu Kush Range, northern Pakistan. J. Asian Earth Sci. 62, 720-733.

Lee, S., 2005. Application of logistic regression model and its validation for landslide susceptibility mapping using GIS and remote sensing data. Int. J. Remote Sens. 26 (7), 1477-1491.

Lee, S., Choi, J., 2004. Landslide susceptibility mapping using GIS and the weight-ofevidence model. Int. J. Geogr. Inf. Sci. 18, 789-814.

Liu, J.G., Masona, P.J., Clerici, N., Chen, S., Davis, A., Miao, F., Deng, H., Liang, L., 2004. Landslide hazard assessment in the Three Gorges area of the Yangtze river using ASTER imagery: Zigui-Badong. Geomorphology 6, 171-187.

Mahmood, S.A., Gloaguen, R., 2012. Appraisal of active tectonics in Hindu Kush: insights from DEM derived geomorphic indices and drainage analysis. Geosci. Front. 3 (4), 407-428.

Manzo, G., Tofani, V., Segoni, S., Battistini, A., Catani, F., 2012. GIS techniques for regionalscale landslide susceptibility assessment: the Sicily (Italy) case study. Int. J. Geogr. Inf. Sci. iFirst 1-20.

Maroukian, H., Gaki-Papana, K., Karymbalis, E., Vouvalidis, K., Pavlopoulos, K., Papanastassiou, D., Albanakis, K., 2008. Morphotectonic control on drainage network evolution in the Perachora Peninsula, Greece. Geomorphology 102, 81-92.

Mathew, J., Jha, V.K., Rawat, G.S., 2007. Application of binary logistic regression analysis and its validation for landslide susceptibility mapping in part of Garhwal Himalaya, India. Int. J. Remote Sens. 28 (10), 2257-2275.

Mejia-Navarro, M., Wohl, E.E., Oaks, S.D., 1994. Geological hazards, vulnerability, and risk assessment using GIS: model for Glenwood Springs, Colorado. Geomorphology 10, 331-354.

Molnar, P., England, P., 1990. Late Cenozoic uplift of mountain ranges and global climate change: chicken or egg. Nature 63, 1117-1142.

Mousavi, S.Z., Kavian, A., Soleimani, K., Mousavi, S.R., Shirzadi, A., 2011. GIS-based spatial prediction of landslide susceptibility using logistic regression model. Geomatics Nat. Hazards Risk 2, 33-50.

Pike, R.J., Wilson, S.E., 1971. Elevation-relief ratio hypsometric integral and geomorphic area-altitude analysis. Geol. Soc. Am. Bull. 82, 1079-1084

Pradhan, B., 2010. Remote sensing and GIS-based landslide hazard analysis and crossvalidation using multivariate logistic regression model on three test areas in Malaysia. Adv. Space Res. 45, 1244-1256.

Ramirez-Herrera, M.T., 1998. Geomorphic assessment of active tectonics in the Acambay Graben, Mexican volcanic belt. Earth Surf. Process. Landf. 23, 317-332.

Silva, P.G., Goy, J.L., Zazo, C., 2003. Fault generated mountain fronts in southeast Spain: geomorphologic assessment of tectonic and earthquake activity. Geomorphology 250, 203-226.

Skubalska-Rafajlowicz, E., 2005. A new method of estimation of the box-counting dimension of multivariate objects using space-filling curves. Nonlinear Anal. 63, 1281-1287.

Strahler, A.N., 1952. Hypsometric (area-altitude) analysis of erosional topography. Geol. Soc. Am. Bull. 63, 1117-1142

Wadge, G., 1994. The potential of GIS modeling of gravity flows and slop instability. Int. J. Geogr. Inf. Syst. 2, 143-152.

Whipple, K.X., Kirby, E., Brocklehurst, S.H., 1999. Geomorphic limits to climate-induced increases in topographic relief. Nature 401, 39-43.

Zhong, D.L., Xie, H., Wang, S.G., 2004. Debris Flow in Beijing Mountain Area. Commercial Press, Beijing (in Chinese). 